\title{
A LEGITIMIDADE DO EXERCÍCIO DE PODER DE POLÍCIA EM TEMPOS DE PANDEMIA
}

\author{
Fernando Navarro Vince ${ }^{1}$ \\ Valter Moura do Carmo ${ }^{2}$
}

\section{RESUMO}

A proteção da saúde pública autoriza o Estado a adotar medidas restritivas de direitos individuais. Esse poder não é ilimitado. Diante de situações graves, a atuação deve ser proporcional e respeitar valores constitucionais. O objetivo deste trabalho foi verificar a legitimidade da conduta estatal no combate a pandemias. Desenvolveu-se pesquisa bibliográfica, com o método de abordagem dedutivo, partindo de análise genérica e confirmando no caso específico do Covid-19. Como resultados, observou-se que o poder público deve se orientar pela satisfação do interesse coletivo. Concluiu-se que a coerção será legítima desde que realizada com proporcionalidade e atenção aos preceitos essenciais.

PALAVRAS-CHAVE: Poder de Polícia; Restrição de direitos fundamentais; Proporcionalidade; Pandemias; COVID-19.

\section{THE LEGITIMACY OF POLICE POWER EXERCISE IN PANDEMIC TIMES}

\begin{abstract}
The protection of public health authorizes the State to adopt measures that restrict rights. This power is limited. In situations, action must be proportionate and respect constitutional values. The objective this paper was to verify the legitimacy of state conduct in combating pandemics. Bibliographic research was developed, using the deductive approach method, starting from generic analysis, and confirming in the Covid-19. As a result, it was observed that the public power must be guided by the satisfaction of the collective interest. It was concluded that, coercion be legitimate provided is carried out with proportionality and attention to the essential precepts.
\end{abstract}

KEY WORDS: Police power; Restriction of Fundamental Rights; Proportionality; Pandemics; COVID-19.

\footnotetext{
${ }^{1}$ Doutorando em Direito na Universidade de Marília - UNIMAR. Mestre em Ciência Jurídicas pela UniCesumar. Especialista em Direito do Estado pela Universidade Estadual de Londrina (UEL). Especialista em Gestão Pública pela Faculdade Educacional de Colombo (FAEC). Graduado em Direito pela Universidade Estadual de Londrina (UEL). Professor da Graduação em Direito da Faculdades Londrina. Professor de Direito Constitucional e Processual Civil dos programas de Pós-graduação Lato Sensu (Especialização) do Instituto de Direito Constitucional e Cidadania (IDCC) Londrina/PR e da Faculdade Alvorada, Maringá/PR. E-mail: fernandonavarrovince@gmail.com

${ }^{2}$ Possui mestrado em Direito Constitucional pela UNIFOR com período sanduíche na Universidade Federal de Santa Catarina - UFSC e doutorado em Direito pela UFSC, tendo realizado o doutorado sanduíche na Universidade de Zaragoza (Espanha) com bolsa do PDSE da CAPES e período de investigação na Universidade Federal da Paraíba - UFPB com bolsa do PROCAD da CAPES. Realizou estágio de pós-doutorado na Universidade de Marília - UNIMAR. Professor permanente do Programa de Pós-Graduação em Direito da UNIMAR. Diretor de relações institucionais do CONPEDi. E-mail: vmcarmo86@gmail.com
} 


\section{INTRODUÇÃO}

Com o advento da pandemia do novo Coronavírus (Covid-19), surgiu a necessidade de o Estado brasileiro editar atos normativos para prevenir e controlar a doença. Essas medidas invariavelmente determinam restrições a direitos fundamentais.

Em que pese a atuação do poder público conter respaldo legal, nota-se que o exercício do poder de polícia não é ilimitado, vez que, pelo fato de atentar contra liberdades garantidas no texto constitucional, deverá a intervenção obedecer ao equilíbrio entre autoridade e liberdade, mais precisamente, atender ao princípio da proporcionalidade.

Embora o assunto proposto tenha sido objeto de análise pelos mais variados prismas (políticos, econômicos, sociais e até jurídico), a matéria ainda carece de uma investigação que leve em conta os preceitos doutrinários tradicionais e contemporâneos dos direitos administrativo e constitucional.

O presente trabalho objetiva examinar a legitimidade da intervenção estatal limitadora de direitos fundamentais. De forma mais específica, verificar a compatibilidade do exercício do poder de polícia em tempos de urgência epidemiológica com a atual quadra de desenvolvimento do ordenamento jurídico vigente. Para tanto, parte-se da premissa de que existe uma relação intensa e dependente entre as liberdades individuais e os atos de império, pois um limita o outro.

A perquirição considera como marco teórico as ideias de importantes juristas que transitam pelo direito público como Paulo Bonavides, Celso Celso Antonio Bandeira de Mello, Ingo Sarlet, Carvalho Filho, José Joaquim Gomes Canotilho, Robert Alexy, dentre outros.

Diante do problema apresentado e do conflito de expectativas e teorias já existentes, adotou-se o método de abordagem hipotético-dedutivo, a partir de pesquisa bibliográfica com o levantamento de referências teóricas publicadas por meios impressos e eletrônicos.

Com base nesse aporte teórico e metodológico, dividiu-se o trabalho em três etapas. Na primeira parte, analisa-se o poder de polícia como ferramenta estatal para frenar direitos individuais em prol do interesse público. Na segunda parte, aborda-se os direitos fundamentais como garantias constitucionais a impedir a ilegítima interferência do poder público na esfera particular. Na terceira e última parte, faz-se uma análise sobre a 
legitimidade do poder ordenador do Estado em tempos de pandemia, mais especificamente uma observação sobre a pertinência constitucional do comportamento restritivo.

\section{PODER DE POLÍCIA}

O termo poder de polícia refere-se à tradução da expressão inglesa police power, que apareceu pela primeira vez no cenário jurídico contemporâneo no julgamento do caso Brown versus Maryland, pela Suprema Corte dos Estados Unidos em 1827. Discutia-se a possibilidade de os Estados-membros editarem leis que limitassem direitos em prol do interesse público. No Brasil, a referida locução começou a ser utilizada a partir de parecer jurídico emitido por Rui Barbosa ${ }^{3}$ em 1915, que relacionava o instituto à garantia da ordem, tranquilidade e saúde públicas (MEDAUAR, 2018, p. 334).

O conceito doutrinário de poder de polícia pode ser representado pelas palavras de Marcelo Caetano:

É o modo de atuar da autoridade administrativa que consiste em intervir no exercício das atividades individuais suscetíveis de fazer perigar interesses gerais, tendo por objeto evitar que se produzam, ampliem ou generalizem os danos sociais que a lei procura prevenir. (CAETANO, 1997, p. 339).

Por ser o exercício dessa atividade interventora fato gerador da taxa, sua conceituação legal é trazida pelo art. 78 do Código Tributário Nacional:

Art. 78 Considera-se poder de polícia atividade da administração pública que, limitando ou disciplinando direito, interesse ou liberdade, regula a prática de ato ou abstenção de fato, em razão de interesse público concernente à segurança, à higiene, à ordem, aos costumes, à disciplina da produção e do mercado, ao exercício de atividades econômicas dependentes de concessão ou autorização do Poder Público, à tranquilidade pública ou ao respeito à propriedade e aos direitos individuais ou coletivos. (BRASIL, 1966).

\footnotetext{
${ }^{3}$ No livro de Odete Medauar acima referenciado, o nome do ilustre jurista baiano consta como "Ruy Barbosa", porém, a grafia correta é Rui Barbosa, conforme orientação da Casa de Rui Barbosa, disponível no sítio http://www.casaruibarbosa.gov.br/interna.php?ID_S=20\&ID_M=1006, motivo pelo qual opta-se por essa designação.
} 
Pelas definições acima, nota-se que atividade administrativa tem por elemento essencial a limitação de direitos fundamentais em prol da proteção do interesse público, ou seja, atuação estatal de compatibilização da liberdade individual aos desejos coletivos.

O objeto do poder de polícia pode ser dividido sob dois aspectos: determinações de ordens públicas ou consentimentos dispensados aos indivíduos. O primeiro se apresenta quando a vontade da administração pública é imposta, de modo a criar obrigações aos cidadãos. Já o segundo, se concretiza por meio de resposta positiva do poder público às solicitações formuladas pelos indivíduos (CARVALHO FILHO, 2017, p. 88).

A satisfação do interesse público é o fundamento, o pressuposto lógico da ordenação estatal. Aliás, o bem comum traduz única e inescapável justificativa da intervenção do Estado nos direitos individuais. Vale dizer, ausente a finalidade comunitária, arbitrário será o ato oficial.

Outro ponto que merece destaque no estudo do poder de polícia é o fato de que, na maioria dos casos, a limitação dependerá de atuação discricionária, pois, diante da impossibilidade da lei prever todas as hipóteses realizáveis no mundo fático, a própria norma, excepcionalmente, mune o administrador público com mecanismos providos de liberdade de escolha.

Nesse sentido é a lição de Celso Antônio Bandeira de Mello:

Será discricionária quando a lei haja deixado ao administrado a faculdade, que é simultaneamente um dever, de verificar concretamente o melhor modo de satisfazer o mandamento legal, ou seja, quando a extensão da liberdade individual não haja sido delimitada legalmente em termos de tipificação aferível segundo critério objetivo, rígido, inconfutável. (BANDEIRA DE MELLO, 2013, p. 836).

Em que pese a possibilidade de atuação do agente estatal com certa margem de liberdade (conveniência e oportunidade), a obediência à lei e ao interesse público permanecem inabaláveis, sob pena de arbitrariedade. A propósito, esclarece o mencionado administrativista:

Não se confundem discricionariedade e arbitrariedade. Ao agir arbitrariamente o agente está agredindo a ordem jurídica, pois terá se comportado fora do que lhe permite a lei. Seu ato, em consequência, é ilícito e por isso mesmo corrigível judicialmente. Ao agir discricionariamente o agente estará, quando a lei lhe outorgar tal faculdade (que é simultaneamente um dever), cumprindo a determinação normativa de ajuizar sobre o melhor meio de dar satisfação ao interesse público por força da indeterminação 
quanto ao comportamento adequado à satisfação do interesse público no caso concreto. (BANDEIRA DE MELLO, 2013, p. 436-437).

O poder ordenador traduz possibilidade de relativização de direitos fundamentais em razão do interesse público. Contudo, essa faculdade não é plena, vez que inexiste em nosso ordenamento direito absoluto, por mais relevante que se apresente. Dito de forma direta: o poder de limitar do Estado não é ilimitado!

Além desses limites (lei e interesse público), os direitos fundamentais consubstanciam importante barreira ao exercício inadvertido da ingerência estatal.

\section{DIREITOS FUNDAMENTAIS COMO LIMITES JURÍDICOS DO PODER DE POLÍCIA}

A expressão "direitos fundamentais" foi construída na França durante o movimento político que originou a Declaração Universal dos Direitos dos Homens e do Cidadão, de 1789 (PÉREZ LUÑO, 1995, p. 30). Sua concepção atual, entretanto, é fruto da reunião de várias fontes históricas, culturais e políticas. Ao analisar os elementos que contribuíram para sua formação, nota-se a presença de dois pontos em comum, quais sejam: a limitação do poder do Estado e a consagração dos princípios da igualdade e da legalidade (MORAES, 2011, p. 01). Em outras palavras, apenas existirão direitos fundamentais quando a autoridade e a liberdade se distinguirem e, até, em maior ou menor medida, se contraporem (MIRANDA, 2014, p. 16).

Com o passar dos tempos, houve uma mudança no modo de interpretar as relações entre indivíduo e poder, considerando que os direitos do homem são históricos, caracterizados por lutas em defesa de novas liberdades em face de velhos poderes, e nascidos de modo gradual, não todos de uma vez e nem de uma vez por todas (BOBBIO, 2004, p. 05).

Nos séculos XVIII e XIX existia somente uma concepção das liberdades individuais, qual seja, a liberal, que não obstante as críticas legitimistas, socialistas ou católicas, era o liberalismo que prevalecia em todas as Constituições e declarações, e era ele a que se reportavam, de uma maneira ou outra, as interpretações da liberdade individual (MIRANDA, 2014, p. 31). Já nos séculos XX e XXI, o quadro se alterou. Passa-se a enxergar, nesse momento, o fenômeno da universalização dos direitos humanos e do poder soberano e vinculante da Constituição. Nesse sentido, René Maheu apud Miranda, ressalta que: 
Se pode antever uma civilização do universal, também dos direitos das pessoas, equivalente ao ideal comum a atingir, de que fala a Declaração Universal, pelo menos por agora, afiguram-se irredutíveis as sensibilidades e as valorações (seja qual for a sua base), que se sustentam nos diversos povos a respeito dos direitos e deveres do homem e do Estado. Isto não impede (nem tem impedido) que se atinjam patamares e convergências de garantia e efetivação. (MIRANDA, 2014, p. 32).

Aparece, nesse momento histórico, o Estado liberal, representado pela limitação do poder estatal pela lei e pela repartição das funções públicas (executivo, judiciário e legislativo). Esse modelo de governo recebeu influência dos pensadores que inspiraram a Revolução Francesa e Norte-americana (John Locke, Montesquieu, Rousseau, Thomas Jefferson) e distinguia-se do modelo anterior (monarquia absolutista) no qual os três poderes se concentravam nas mãos de um só (FACHIN, 2013, p. 41).

Suas principais características eram: os direitos fundamentais, principalmente liberdade e propriedade previstos apenas de maneira formal e concedidos somente para parte da sociedade. As camadas inferiores não eram agraciadas com todas as garantias; a atuação do Poder Público somente acontecia mediante previsão legislativa; o Estado também se submete à norma; a função do Poder Público se restringe à proteção da ordem e segurança pública, ficando os domínios econômico e social a cargo da liberdade individual; Estado mínimo, de intervenção mínima, caracterizado pela abstenção (FACHIN; VINCE, 2017, p. 40).

Constata-se uma domesticação do domínio político pelo direito (CANOTILHO, 2003, p. 93), consubstanciada pela diminuição da atuação do Estado nas relações sociais. Todavia, esse afastamento trouxe consequências negativas. Diante da abstenção do Poder Público, a liberdade negocial indiscriminada trouxe à tona as desigualdades sociais. A liberdade produziu, por exemplo, “[...] a desumana espoliação do trabalho, o doloroso emprego de métodos brutais de exploração econômica, a quem nem a servidão medieval se poderia, com justiça, equiparar" (BONAVIDES, 2011, p. 59).

Os direitos fundamentais podem ser compreendidos como direitos que pertencem, ou deveriam pertencer, a todos os homens, ou dos quais nenhum homem pode ser despojado (BOBBIO, 2004, p. 17).

Para Uadi Lâmmego Bulos (2012, p. 512), consistem em um conjunto de normas, princípios, prerrogativas, deveres e institutos, inerentes à soberania popular, que garantem a convivência pacífica, digna, livre e igualitária, independente de credo, raça, origem, cor, condição econômica ou status social. Sem esses direitos públicos subjetivos, arremata o 
citado autor, "[...] o homem não vive, não convive, e, em alguns casos, não sobrevive" (BULOS, 2014, p. 525).

Tratam-se, então, de prerrogativas que a norma jurídica efetiva em garantias de convivência humana digna, livre e para todos.

Deve integrar a conceituação, o princípio da dignidade da pessoa humana, que inspira e fundamenta todos os demais direitos fundamentais, é o fundamento de todos os direitos humanos elevados à categoria de direitos fundamentais pelo ordenamento jurídicoconstitucional (BARBOSA, 2010, p. 94). Em outras palavras, a fundamentalidade dos direitos públicos subjetivos reside/decorre da sua intenção de explicitar e concretizar o princípio basilar da dignidade da pessoa humana (VIEIRA DE ANDRADE, 1987, p. 85).

Isto posto, as liberdades fundamentais correspondem a anseios da sociedade que nascem a cada instante na história a partir da análise do princípio da dignidade. Para o jurista alemão Robert Alexy (2014), os direitos dos homens são definidos por cinco características principais:

A primeira é a sua universalidade. Todo ser humano enquanto ser humano é portador ou possuidor de direitos humanos. Do lado dos destinatários a universalidade é mais complicada. Alguns direitos humanos, como o direito à vida, opõem-se a todos que podem ser destinatários de deveres, ou seja, a todos os seres humanos, mas também a todos os estados e organizações. Outros direitos humanos, como o direito à participação na formação da vontade política, opõem-se meramente contra o Estado ao qual o indivíduo pertence ou no qual ele vive. A segunda característica dos direitos humanos é o caráter fundamental de seu objeto. Os direitos humanos não protegem todas as fontes e condições imagináveis do bem-estar, mas somente interesses e necessidades fundamentais. Também a terceira característica diz respeito ao objeto dos direitos humanos. É a abstração. Pode-se rapidamente concordar que todos possuem um direito à saúde; mas sobre o que isso significa em um caso concreto pode ocorrer uma longa disputa. A quarta e a quinta características não dizem respeito aos portadores, aos destinatários e nem ao objeto dos direitos humanos, mas sim à sua validade. Os direitos humanos possuem, enquanto tais, somente uma validade moral. A quarta característica dos direitos humanos é, assim, seu caráter moral. Um direito vale moralmente se ele pode ser justificado em relação a todo aquele que admite uma fundamentação racional. A validade dos direitos humanos é sua existência. A existência dos direitos humanos consiste por essa razão em sua fundamentabilidade e em nada mais. Naturalmente pode-se juntar à validade moral dos direitos humanos uma validade jurídico-positiva. Quinta característica, a prioridade. Os direitos humanos, enquanto direitos morais, não só não podem ter sua força invalidada por normas jurídico-positivas, mas são também o padrão com o qual se deve medir toda interpretação daquilo que está positivado. Isso significa que um pacto de direitos humanos, bem como uma decisão de uma corte de direitos humanos pode violar os 
direitos humanos. Com isso estão juntas as cinco características que distinguem os direitos humanos de todos os outros direitos: direitos humanos são direitos (1) universais, (2) fundamentais, (3) abstratos, (4) morais e (5) prioritários. (ALEXY, 2014, p. 146-148).

Os direitos fundamentais exercem várias funções na sociedade e no ordenamento jurídico. Para fins didáticos, com intuito de facilitar o entendimento, a doutrina, a partir das ideias do constitucionalista alemão Georg Jellinek (DIMOULIS; MARTINS, 2011, p. 58), dividiu as finalidades de acordo com a forma de atuação frente ao Estado e classificou-os como direitos de defesa, de prestação e de participação.

A primeira classificação, qual seja, os direitos de defesa ou de resistência traduzem um dever de abstenção que impede a intromissão do Estado no espaço de autodeterminação do indivíduo (VIEIRA DE ANDRADE, 1987, p. 192). Restringem o poder da autoridade para conservar as liberdades individuais, agindo como regras de competência negativa.

No que tange os direitos à prestação, esses diferenciam-se dos direitos de defesa, uma vez que estes estabelecem uma abstenção, uma omissão, enquanto os direitos à prestação visam garantir aos cidadãos um comportamento proativo por parte do Estado. Nascem da premissa que a administração pública deve agir para libertar os indivíduos das necessidades (MENDES; BRANCO, 2015, p. 259). São criados com a intenção de implantar “[...] uma igualdade efetiva e solidária entre todos os membros da comunidade política (CANOTILHO, 2003, p. 1.128).

Por fim, tem-se os direitos de participação. Antes de mais nada, um registro em relação a essa função das liberdades públicas. Existem doutrinadores ${ }^{4}$ que incluem essa finalidade ao lado dos direitos de defesa ou ao lado dos direitos à prestação. Mesmo os que entendem que esses direitos pertencem a uma terceira categoria própria - como aqui se faz admitem, contudo, a característica híbrida dos mesmos (defesa + prestação). Trata-se, nos termos de Dimitri Dimoulis e Leonardo Martins (2011, p. 61), de direitos ativos porque possibilitam uma intromissão do cidadão na seara política decidida pelas autoridades do Estado. $\mathrm{O}$ aspecto político dos direitos do homem constitui o fundamento da democracia, vez que efetivam a contribuição popular nas decisões do Estado.

A doutrina dominante atribui aos direitos fundamentais duas dimensões, a subjetiva e a objetiva. A primeira preconiza o status negativus, remonta às origens do constitucionalismo

\footnotetext{
${ }^{4}$ Canotilho e Alexy entendem que os direitos políticos, de acordo com sua conformação e peculiaridades, localizam-se entre os direitos de defesa e prestação (MENDES; BRANCO, 2015. p. 166).
} 
e traduzia a função clássica de limitação dos direitos dos homens, agindo, os sobreditos direitos, como garantias de resistência à intervenção estatal. Refere-se ao direito de defesa, anteriormente estudado, que induz e obriga a uma abstenção ao Estado.

Ao lado dessa perspectiva omissiva localiza-se a dimensão objetiva, que resulta do significado das garantias individuais como ordem de prevalência superior dentro do sistema jurídico, o que faz com que seus valores influenciem todas as áreas do ordenamento e funcionem como fator norteador a balizar a atividade hermenêutica. A concretização dos direitos humanos configura uma pretensão moral que transcende qualquer norma positivada pelo sistema para tentar justificar a sua existência (LIMA; CROCETTA, 2019, p. 04).

Os direitos naturais ultrapassam, assim, o aspecto da garantia de posições individuais para alcançar a estatura de normas que filtram os valores básicos da sociedade política, expandindo-os para todo o direito positivo (MENDES; BRANCO, 2015, p. 167). A dimensão objetiva implica, desta maneira, eficácia "irradiante", que transforma os preceitos fundamentais em diretrizes para a interpretação e aplicação das normas dos demais ramos do Direito.

Sobre a matéria, oportunas são as ideias de Ingo Sarlet:

A dimensão objetiva dos direitos fundamentais liga-se ao reconhecimento de que tais direitos, além de imporem certas prestações aos poderes estatais, consagram também os valores mais importante sem uma comunidade política, constituindo, como afirmou Konrad Hesse, "as bases da ordem jurídica da coletividade". Nesta linha, quando se afirma a existência desta dimensão objetiva pretende-se, como registrou Vieira de Andrade que os direitos fundamentais não podem ser pensados apenas do ponto de vista dos indivíduos, enquanto faculdades ou poderes de que estes são titulares, antes valem juridicamente também do ponto de vista da comunidade, como valores ou fins que esta se propõe a prosseguir (SARLET, 2012, p. 127).

Nota-se, entretanto, que a dimensão objetiva dos direitos do homem representa decisões valorativas de natureza jurídico-objetiva estampadas na Lei Maior que se lançam por todo o sistema jurídico. Dito de outra forma, os direitos fundamentais passaram a apresentarse, no âmbito da ordem constitucional, como um conjunto de valores objetivos a direcionar a conduta positiva do Poder Público e não somente as garantias negativas dos interesses dos indivíduos.

Diante do relevo valorativo que os direitos fundamentais representam, sua constante proteção é medida que se impõe e sua restrição pelo poder de polícia somente será legítima 
em casos excepcionais e desde que presentes os requisitos ensejadores da extraordinária intervenção.

\section{A LEGITIMIDAde do EXERCíCIO DE PODER DE POLÍCIA EM TEMPOS DE PANDEMIA}

Os tópicos anteriores levam à constatação de que poder de polícia e direitos fundamentais se relacionam intrinsecamente e atuam de forma que um limita o outro. Ou seja, a atuação ordenadora do Estado pode restringir liberdades individuais, mas por elas também é limitado, na medida em que o poder público, durante sua atividade regulatória, não poderá se afastar dos valores albergados na Constituição e provocar a aniquilação das garantias alcançadas.

Verifica-se então o problema: quando a intervenção estatal limitadora de direitos fundamentais será legítima? Quando existir equilíbrio entre autoridade e liberdade. Quando houver efetiva e real supremacia do interesse coletivo. Quando a coerção mantiver fina sintonia entre as razões e os objetivos que a fundamentam. Em síntese, quando a atuação do poder público for proporcional. Explica-se.

Antes de adentrar na investigação da proporcionalidade na seara da administração pública, tema de interesse do artigo, necessárias algumas considerações gerais sobre esse importante postulado jurídico.

Existem princípios que são mais fáceis de compreender do que de conceituar. A proporcionalidade é um deles. Ela esteve presente em diversos ramos do Direito, seja na aplicação da pena criminal, seja na noção de abuso do civilista ou, ainda, como meio de conter a discricionariedade do Poder Estatal no âmbito administrativo (TAVARES, 2015, p. 629). Personificava, o referido dogma, a exigência de racionalidade, a obrigação de que a conduta do poder público sempre fosse provida de uma parcela mínima de sustentabilidade racional.

O conceito de proporcionalidade foi empregado pela primeira vez em 1802, por Von Berg, na Alemanha, e somente depois de um século, foi efetivamente utilizado no campo do Direito de Polícia, por obra do Superior Tribunal Administrativo da Prússia. Cumpre ressaltar ainda acerca da jurisprudência constitucional da Alemanha onde, muito cedo, sedimentou-se o entendimento de que a proporcionalidade consubstanciava relevante meio de controle estatal, 
visando a observância e concretização dos direitos fundamentais do cidadão (ANTUNES, 2006, p. 11).

Para Paulo Bonavides (2006, p. 393), o aludido princípio possui dois principais sentidos: amplo e restrito. Em sentido mais amplo, é a regra fundamental a quem devem obedecer tanto aos que exercem, quanto os que padecem do poder. Numa dimensão menos larga, se caracteriza pelo fato de presumir a existência da relação adequada entre um ou vários fins determinados e os meios que são levados a cabo. Logo, nesta última acepção, haverá violação do princípio toda vez que os meios destinados a realizar um fim não são por si mesmos apropriados, e/ou quando a desproporção entre meios e fim é particularmente evidente ou manifesta.

Será proporcional a opção que melhor atender a tarefa de otimização das regras em disputa, considerando-se que cada qual apresenta pesos variáveis de importância conforme o caso concreto que esteja em exame (HESSE, 1983, p. 46).

Dessa forma, o princípio da proporcionalidade, conhecido por limite dos limites, atua como ferramenta indispensável para impingir a legitimidade e a adequação das normas com os ditames da justiça e da razão. Todavia, o exercício do referido método interpretativo não pode ser realizado de forma crua, pouco elaborada e com base em critérios subjetivos. $\mathrm{O}$ referido postulado possui dimensões que condicionam a sua aplicação e eliminam o perigo da subjetividade. Essas dimensões são concretizadas por meio da observação dos subprincípios da adequação, necessidade e proporcionalidade em sentido estrito.

No artigo “O proporcional e o razoável”, Luis Virgílio Afonso da Silva aborda assim o assunto:

A real importância dessa ordem fica patente quando se tem em mente que a aplicação da regra da proporcionalidade nem sempre implica a análise de todas as suas três sub-regras. Pode-se dizer que tais sub-regras relacionam-se de forma subsidiária entre si. Essa é uma importante característica, para a qual não se tem dado a devida atenção. A impressão que muitas vezes se tem, quando se mencionam as três sub-regras da proporcionalidade, é que o juiz deve sempre proceder à análise de todas elas, quando do controle do ato considerado abusivo. Não é correto, contudo, esse pensamento. É justamente na relação de subsidiariedade acima mencionada que reside a razão de ser da divisão em sub-regras. Em termos claros e concretos, com subsidiariedade quer-se dizer que a análise da necessidade só é exigível se, e somente se, o caso já não tiver sido resolvido com a análise da adequação; e a análise da proporcionalidade em sentido estrito só é imprescindível, se o problema já não tiver sido solucionado com as análises da adequação e da necessidade. Assim, a aplicação da regra da proporcionalidade pode esgotar-se, em alguns casos, com o simples exame da adequação do ato 
estatal para a promoção dos objetivos pretendidos. Em outros casos, pode ser indispensável a análise acerca de sua necessidade. Por fim, nos casos mais complexos, e somente nesses casos, deve-se proceder à análise da proporcionalidade em sentido estrito. (SILVA, 2002, p. 34).

Por adequação entende-se que devem ser utilizadas medidas apropriadas para alcançar a finalidade prevista no mandamento. Deve-se perguntar se o meio escolhido foi pertinente para atingir o resultado almejado. Se não, desrespeitou-se o princípio da proporcionalidade e a escolha será ilegítima. Exige-se, assim, que a opção adotada seja apta a alcançar os objetivos pretendidos. O aplicador da norma examinará se o meio é "simplesmente inadequado", "objetivamente inadequado", "manifestamente inadequado ou desnecessário", "fundamentalmente inadequado", ou se "com sua utilização o resultado pretendido pode ser estimulado" (MENDES; BRANCO, 2015, p. 332).

Em relação ao segundo subprincípio, a necessidade, exige-se que a decisão escolhida seja a que produz menor prejuízo para o cidadão e para a coletividade, não podendo ser excessiva, nem tampouco insuficiente. Nem de mais, nem de menos. Em outros termos, o meio não será necessário se o objetivo almejado puder ser alcançado com a adoção de medida que se revele, a um só tempo, adequada e menos onerosa (MENDES; BRANCO, 2015, p. 333). Um ato estatal que limita um direito fundamental é somente necessário caso a realização do objetivo perseguido não possa ser promovida, com a mesma intensidade, por meio de outro ato que limite, em menor medida, o direito fundamental atingido (SILVA, 2002, p. 38). Em arremate, no tocante à proporcionalidade em sentido estrito, analisa-se as vantagens e desvantagens que a medida trará. Lado positivo e negativo. Deve-se indagar se o benefício alcançado com a adoção da medida sacrificou direitos fundamentais mais importantes do que os que a medida buscou preservar. Não haverá proporcionalidade, na sua vertente estrita, se o que se perde com a conduta é de maior relevo do que aquilo que se ganha (BARROSO, 2014, p. 375).

Assim sendo, forçoso concluir que, ainda que uma medida que limite um direito fundamental seja adequada e necessária para promover outro valor constitucional, isso não demonstra, por si só, que ela deve ser considerada como proporcional. Necessário é esse terceiro e derradeiro exame, que consiste em um sopesamento entre a intensidade da restrição ao direito fundamental atingido e a importância da realização do direito fundamental que com ele colide e que fundamenta a adoção da medida restritiva. 
Feitas essas ponderações sobre o princípio da proporcionalidade, passa-se a abordar a inserção desse tema dentro do contexto ora investigado.

Para serem legítimas, as medidas de limitação de direitos devem manter congruência com os motivos e fins que as justificam (MEDAUAR, 2018, p. 337). Será necessário que o Estado tenha cuidado ao agir, nunca se servindo de meios mais enérgicos que os necessários à obtenção do resultado pretendido pela lei (BANDEIRA DE MELLO, 2013, p. 589).

Como assevera José dos Santos Carvalho Filho:

O princípio da proporcionalidade deriva, de certo modo, do poder de coerção de que dispõe a Administração ao praticar atos de polícia. Realmente, não se pode conceber que a coerção seja utilizada indevidamente pelos agentes administrativos, o que ocorreria, por exemplo, se usada onde não houvesse necessidade. Em virtude disso, tem a doutrina moderna mais autorizada erigido à categoria de princípio necessário à legitimidade do ato de polícia a existência de uma linha proporcional entre os meios e os fins da atividade administrativa. (CARVALHO FILHO, 2017, p. 91).

Se o comportamento desrespeita o razoável, o resultado é que algumas pessoas são prejudicadas pelo abuso de poder, demonstrando, assim, ofensa ao interesse público, alvo pretendido pelo Estado. Exige-se adequação dos meios aos fins. Isto, ademais, não é novidade. É velho e se conserva novo, atual, porque é indispensável à busca do equilíbrio entre o direito individual e o interesse público (PIETRO, 2018, p. 85-86).

O direito administrativo foi concebido a partir de duas vigas-mestras: autoridade e liberdade. A primeira é necessária de decorrência lógica do primado da supremacia do interesse coletivo. Sem ela não há como vingar a ordem pública. Já a segunda, representa

o muro de contenção a impedir a ilegítima interferência do Estado na esfera individual. Sem ela não se estabelece o Estado de Direito.

A restrição administrativa que reprime direitos públicos subjetivos não pode ultrapassar o necessário para a concretização do desejo social que busca defender, haja vista que o objetivo não é reprimir os direitos dos cidadãos, ao revés, garantir a sua fruição, adequando-o ao bem da sociedade.

A coerção das liberdades públicas somente poderá ocorrer para tutelar interesses considerados maiores no caso concreto e exatamente no grau necessário ao atingimento da finalidade pública, sempre atento à forma menos invasiva para o cidadão. 
Ademais, pela excepcionalidade, o exercício da atividade oficial restritiva somente terá espaço nos casos de perigo real de dano social. Por outras palavras, deve estar presente entre a coibição e prejuízo impedido, refutando-se, assim, atos desproporcionais ou em desacordo com o bem protegido.

No que concerne à saúde, tem-se que se trata de preceito social fundamental previsto especialmente nos artigo $6^{\circ}$ e 196 da Constituição Federal de 1988, que decorre logicamente dos dois principais direitos do ser humano, a vida e a existência digna. Essa constitucionalização consubstancia expressão do quilate jurídico que contempla a ordem social numa época que a subjetivação se atrela à normatização, que apontam para a concretização de um real Estado Democrático de Direito.

Incluído no rol de direitos denominados de segunda dimensão, essa prerrogativa constitucional caracteriza-se por outorgar ao indivíduo acesso a prestações estatais, revelandose como transição entre as liberdades formais abstratas para liberdades materiais concretas (SARLET 2012, p. 47-48). Dispõe então, o direito humano supracitado, de uma dúplice vertente, sendo a primeira negativa ou omissiva, em que o Estado deve abster-se de práticas que prejudiquem a saúde do cidadão, e a segunda, positiva ou comissiva, que impõe ao Governo a adoção de ações que visem garantir o antevisto direito social.

Como se observa, incumbe ao ente estatal a implementação de políticas públicas que proporcione à pessoa o mínimo de bem-estar. Por outras palavras, a efetividade e concretização do direito à saúde depende da vontade política dos dirigentes e da atuação proativa da Administração Pública.

Consoante lição de Canotilho, "as normas de direitos fundamentais à prestação são, em rigor, normas programáticas, isto é: regras juridicamente vinculativas que podem obrigar a uma 'política' ativa, sem, contudo, fundamentarem pretensões de prestação subjetivas" (CANOTILHO, 2003, p. 475).

Destarte, extrai-se do comando legal que o respeito à higidez física é um direito do indivíduo e um dever do Estado, pois, sem saúde, a dignidade e a vida, são ofertadas pela metade, o que se perfaz inconcebível e intolerável perante a atual posição que esse considerável postulado ocupa na moderna escala valorativa normativa.

Sendo proteção à saúde um interesse público e obrigação do Estado, logo, poderá ser objeto de exercício do poder de polícia. 
Ademais, a vigilância epidemiológica, definida pela Lei $\mathrm{n}^{\circ}$ 8.080/90 como "um conjunto de ações que proporciona o conhecimento, a detecção ou prevenção de qualquer mudança nos fatores determinantes e condicionantes de saúde individual ou coletiva, com a finalidade de recomendar e adotar as medidas de prevenção e controle das doenças ou agravos" decorre da obrigação constitucional de proteção à saúde (BRASIL, 1990, §2 do art. $\left.6^{\circ}\right)$

Com efeito, condutas estatais restritivas de direitos fundamentais com base na prevenção e contenção de epidemias podem ser adotadas. Foi o que ocorreu no Brasil em 2006, diante proliferação do mosquito transmissor da dengue, em que a União lançou e pôs em prática o Programa Nacional de Controle da Dengue ${ }^{5}$, que dava amparo legal à execução das ações de campo - imóveis fechados, abandonados ou com acesso não permitido pelo morador.

No caso específico da pandemia do novo coronavírus (COVID-19) ${ }^{6}$, o Governo Federal, escorado no interesse social, tem editado atos normativos ${ }^{7}$ que estabelecem medidas necessárias para enfrentamento da doença. Essa conduta vem afetando vários direitos individuais $^{8}$. Sem adentrar no mérito das anunciadas restrições - diante da ausência de dados técnicos sobre a enfermidade e em face do exíguo tempo transcorrido desde o seu aparecimento -, verifica-se que esta atuação de poder público é juridicamente possível, por estar fundamentada na lei e no bem estar social, mas apenas será considerada legítima se observar os limites acima dispendidos, notadamente o princípio da proporcionalidade, medida

\footnotetext{
${ }^{5}$ Disponível em http://bvsms.saude.gov.br/bvs/politicas/programa_nacional_controle_dengue.pdf. Acesso em 10 abr. 2020.

${ }^{6}$ Trata-se de uma nova variante do coronavírus, denominada 2019-nCoV, até então não identificada em humanos. Até o aparecimento do 2019-nCoV, existiam apenas seis cepas conhecidas capazes de infectar humanos, incluindo o SARS-CoV e MERS-CoV. Disponível em:

https://www.infectologia.org.br/admin/zcloud/principal/2020/03/Coronavirus_P\&R_24-01.pdf. Acesso em: 10 abr. 2020.

7 Destacam-se Lei Federal 13.979, de 6 de fevereiro de 2020; portaria 356, de 11 de março de 2020, do Ministério da Saúde; portaria interministerial 5 [Estado da Justiça e Segurança Pública e Saúde] de 17 de março de 2020; portaria 454, de 20 de março de 2020, do Ministério da Saúde; decreto Federal 10.282, de 20 de março de 2020.

${ }^{8}$ Exemplos de medidas restritivas: a) isolamento [de pessoas, doentes ou contaminadas; bagagens, meios de transporte, mercadoras, ou encomendas postais]; b) quarentena [restrição de atividades ou separação de pessoas suspeitas de contaminação; bagagens; contêineres; animais; meios de transporte ou mercadorias suspeitos de contaminação]; c) determinação compulsória de exames médicos, testes laboratoriais, coleta de amostras clínicas, vacinação; e tratamentos específicos; d) estudo ou investigação epidemiológica; e) exumação, necropsia, cremação e manejo de cadáver; f) requisição de bens e serviços de pessoas naturais ou jurídicas, com indenização posterior; e g) restrição excepcional e temporária, conforme recomendação técnica da Anvisa, por rodovias, portos ou aeroportos de entrada e saída do país; e locomoção interestadual e intermunicipal (redação da MP 926, de 20 de março de 2020).
} 
suprapositiva das condutas do poder executivo, que proíbe o excesso e preconiza a conformação entre os meios e os fins.

\section{CONSIDERAÇÕES FINAIS}

O artigo tinha por finalidade realizar uma análise sobre a legitimidade da intervenção estatal limitadora de direitos fundamentais diante de casos de pandemia. Outrossim, buscava auferir quais eram as balizas a serem observadas pelo Estado na adoção de medidas restritiva da liberdade.

De início, veio a lume a análise sobre o poder de polícia. Foram abordados seus principais aspectos como origem, conceituação, fundamento, objeto, discricionariedade e limites. Pode-se extrair dali que essa prerrogativa da administração púbica tem assento no princípio da supremacia do interesse público e, por conta disso, tem seu leque de atuação aumentado. Por outras palavras, com estofo no bem maior, pode o ente estatal quase tudo, só não pode dispor dos desejos da coletividade. O poder de limitar é limitado.

Num segundo momento, abordou-se os direitos fundamentais. Para melhor contextualização, destacou-se aspectos da teoria geral que guarda relação com o tema investigado como evolução, concepções, características, finalidades, dimensões subjetivas e objetivas. Vislumbrou-se a relevância das liberdades fundamentais como proteção do indivíduo e elemento direcionador da conduta positiva do poder público. Em arremate, demonstrou-se a possibilidade de afastamento excepcional das garantias, mas a impossibilidade de sua aniquilação.

$\mathrm{Na}$ terceira etapa, chegou-se ao ápice da discussão com a abordagem central do problema apresentado, a saber: quando a intervenção estatal limitadora de direitos fundamentais será legítima? Com supedâneo nos tópicos que o antecederam, foi possível responder a pergunta. A restrição administrativa que atinge direitos subjetivos somente será considerada legítima se eivada de excesso, se atender ao princípio da proporcionalidade e não se desviar dos anseios sociais que busca defender, vez que a finalidade não é reprimir os direitos dos cidadãos, mas proporcionar a sua orientada fruição.

\section{REFERÊNCIAS}

ALEXY, Robert. Teoria Discursiva do Direito. Organização, tradução e estudo introdutório Alexandre Travessoni Gomes Trivisonno. Rio de Janeiro: Forense Universitária, 2014. 
ANTUNES, Roberta Pacheco. O princípio da proporcionalidade e sua aplicabilidade na problemática das provas ilícitas em matéria criminal. São Paulo: Saraiva, 2006.

BANDEIRA DE MELlO, Celso Antônio. Curso de Direito Administrativo. 30. ed. São Paulo: Malheiros, 2013.

BARBOSA, Juliana de Almeida. Estudos sobre a democracia. Estudos - Revista de Ciências Humanas e Sociais Aplicadas da Unimar, Marília/SP, v. 14, p. 85-110, jan./abr. 2010.

Disponível em: http://ojs.unimar.br/index.php/estudos/article/view/825. Acesso em: 10 abr. 2020.

BARROSO, Luís Roberto. Interpretação e aplicação da Constituição: fundamentos de uma dogmática constitucional transformadora. 7. ed. São Paulo: Saraiva, 2014.

BOBBIO, Norberto. A Era dos Direitos. Tradução Carlos Nelson Coutinho. 18. ed. Rio de Janeiro: Elsevier, 2004.

BONAVIDES, Paulo. Curso de Direito Constitucional. 6. ed. São Paulo: Malheiros, 1996.

BONAVIDES, Paulo. Do Estado Liberal ao Estado Social. 10. ed. São Paulo: Malheiros, 2011.

BRASIL. Lei no 5.172/1966, de 27 de outubro de 1966. 2013. Dispõe sobre o Sistema Tributário Nacional e institui normas gerais de direito tributário aplicáveis à União, Estados e Municípios. Diário Oficial da União, Brasília, DF, n. 227, 27. out. 1966. Disponível em: http://www.planalto.gov.br/ccivil_03/leis/15172.htm. Acesso em: 30 mar. 2020.

BRASIL. Lei no 8.080/ 1990, de 20 de setembro de 1990. Dispõe sobre as condições para a promoção, proteção e recuperação da saúde, a organização e o funcionamento dos serviços correspondentes e dá outras providências. Diário Oficial da União, Brasília, DF, 27. set. 1990. Disponível em: http://www.planalto.gov.br/ccivil_03/leis/18080.htm. Acesso em: 30 mar. 2020.

BRASIL. Ministério da Saúde. Secretaria de Vigilância em Saúde. Programa Nacional de Controle da Dengue: amparo legal à execução das ações de campo - imóveis fechados, abandonados ou com acesso não permitido pelo morador. 2. ed. Brasília: Ministério da Saúde, 2006.

BULOS, Uadi Lammêgos. Curso de direito constitucional. 8. ed. São Paulo: Saraiva, 2014.

CAETANO, Marcelo. Princípios fundamentais de direito administrativo. Rio de Janeiro: Forense, 1977.

CANOTILHO, Joaquim José Gomes. Direito constitucional e teoria da constituição. 7. ed. Coimbra: Almedina, 2003.

CARVALHO FILHO, José dos Santos. Manual de direito administrativo. 31. ed. rev., atual. e ampl. São Paulo: Atlas, 2017.

DIMOULIS, Dimitri; MARTINS, Leonardo. Teoria geral dos direitos fundamentais. 3. ed. São Paulo: Revista dos Tribunais, 2011.

FACHIN, Zulmar. Curso de direito constitucional. 6. ed. Rio de Janeiro: Forense, 2013.

FACHIN, Zulmar; VINCE, Fernando Navarro. Aplicação dos direitos fundamentais nas relações particulares: uma análise com base na doutrina nacional e jurisprudência atual do Supremo Tribunal Federal. Toledo: Vivens, 2017. 
HESSE, Konrad. Escritos de derecho constitucional - Selección. Madri: Centro de Estudios Constitucionales, 1983.

LIMA, Fernanda da Silva; CROCETTA. Bruna Baggio. Os direitos humanos a partir de uma perspectiva Intercultural. Revista Argumentum, Marília/SP, v. 20, n. 1, p. 97-111, jan./abr. 2019. Disponível em: http://ojs.unimar.br/index.php/revistaargumentum/article/view/587. Acesso em: 11 abr. 2020.

MEDAUAR, Odete. Direito Administrativo moderno. 21. ed. Belo Horizonte: Fórum, 2018.

MENDES, Gilmar Ferreira; BRANCO, Paulo Gustavo Gonet. Curso de Direito Constitucional. 10. ed. São Paulo: Saraiva, 2015.

MIRANDA, Jorge. Manual de direito constitucional. 5. ed. Coimbra: Coimbra Editora, 2014.

MORAES, Alexandre de. Direitos fundamentais: teoria geral, comentários aos arts. $1^{\circ}$ a $5^{\circ}$ da Constituição da República Federativa do Brasil, doutrina e jurisprudência. 9. ed. São Paulo: Atlas, 2011.

PÉREZ LUÑO, Antonio Enrique. Derechos Humanos, Estado de Derecho y Constitución. Madrid: Tecnos, 1995.

PIETRO, Maria Sylvia Zanella Di. Direito administrativo. 31. ed. rev. atual. e ampl. - Rio de Janeiro: Forense, 2018.

SARLET, Ingo Wolfgang. Eficácia dos Direitos Fundamentais: uma teoria Geral dos direitos fundamentais na perspectiva constitucional. 11. ed. Porto Alegre: Livraria do advogado, 2012.

SILVA, Luís Virgílio Afonso da. O proporcional e o razoável. Revista dos Tribunais, São Paulo, ano 91, n. 798, p. 23-50, abr. 2002.

TAVARES, André Ramos. Curso de direito constitucional. 13. ed. São Paulo: Saraiva, 2015.

VIEIRA DE ANDRADE, José Carlos. Os direitos fundamentais na Constituição portuguesa de 1976, Coimbra: Almedina, 1987. 